\title{
Soft Startup Technology of AC Asynchronous Motor
}

$$
\text { Yujie } \mathrm{CaO}^{1, \mathrm{a}}
$$

${ }^{1}$ School of Electrical and Electric Engineering, North China Electric Power University, Beijing, 102206, China

ahicys610@163.com

\section{Keywords: Asynchronous Motor, Soft Start.}

\begin{abstract}
The current of three-phase asynchronous motor direct startup will reach 5-8 times of its rated current, causing the decrease of operation efficiency and its PFC, even great damage to the trailer system and the grid. Soft start technology can start as shockless and fluent as possible and then reach its best status of startup and pause by adjusting the parameters. This report mainly introduces deficiency of several traditional startup methods widely used in modern industries. And several motor soft start methods are compared based on recent domestic and abroad research results.
\end{abstract}

\section{Introduction}

People require higher startup performance demand on the three-phase asynchronous motor in extensive use. Traditional voltage-reduced start mode has a great deal of abuse; it cannot eliminate the current surge, causing the reducedstartup torque, high maintenance fee and the great power loss etc. With the development of electronic technique, using soft starters can start motors smoothly without impulsion, and then the service life enlarged, maintenance lessened and the profit boost.

\section{Traditional Startup Methods}

Voltage-reducedstartup is one of the commonly used traditional startup methods.The aim for it is to lower down the startup current which reduces startup torque also. So this method cannot be used in the production with heavy load.

It includes star-triangle startup, autotransformer startup, and stator circuit in series with reactor or water resistance startup, and rotor winding in series with the frequency sensitive rheostat or water resistance startup.Their common merit is of no harmonic pollution. However, their weaknesses areobvious;for instance, they are easy to generate secondary impact current, giant, limited-application, with high breakdown rate and high cost for maintenance.

\section{Soft Starter for Startup}

The soft start is a process of voltage-reducedstartup according to the preset control mode. Soft starter is an automatic control element which can complete the measurement and control algorithm with single chip microcomputer as the core of the central controller to automatically control the entire startup process.

With the development of electronic and microcomputer interface technique, a series of electronically startup controlled devices are invented in domestic and abroad, which are used in thestartupcontrol of asynchronous motor to replace Voltage-reducedStartup devices. The main circuit of a new type of electronic soft starter is generally adopted by the thyristor voltage regulating circuit and aided by microcomputer control system. 

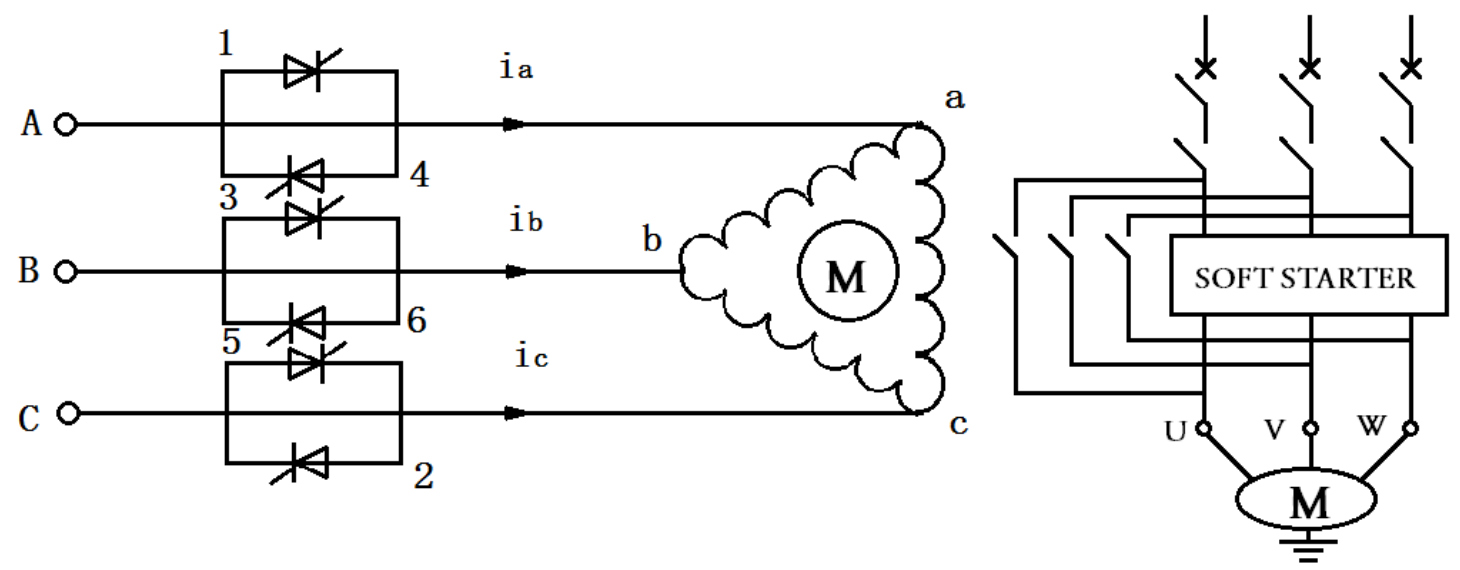

Fig.1 Soft starter schematic wiring diagram

As Fig. 1 indicates, the voltage regulating circuit consists of six thyristors while each two of them parallel with each other in opposite directions. And these combined thyristors are connected to the three phase supplies of the asynchronous motor. When the micro-controller system of the starter receives start instructions, corresponding calculations will be completed and output trigger signals to thyristors. After finishing startup, generally the starter will actuate bypass contactors and short all thyristors to avoid unnecessary power loss to put the motor into gird.

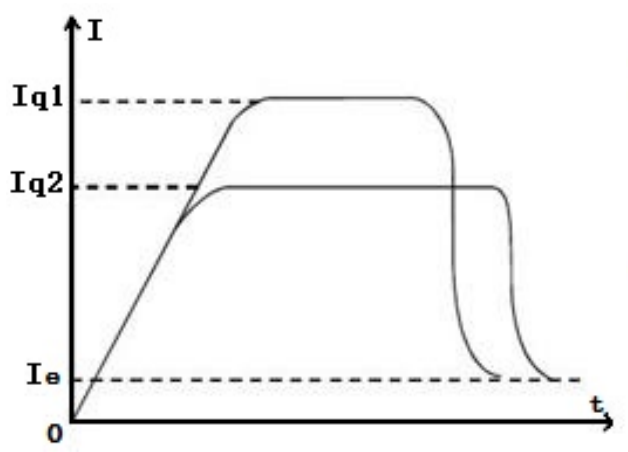

Fig.2 Current-limitedstartup

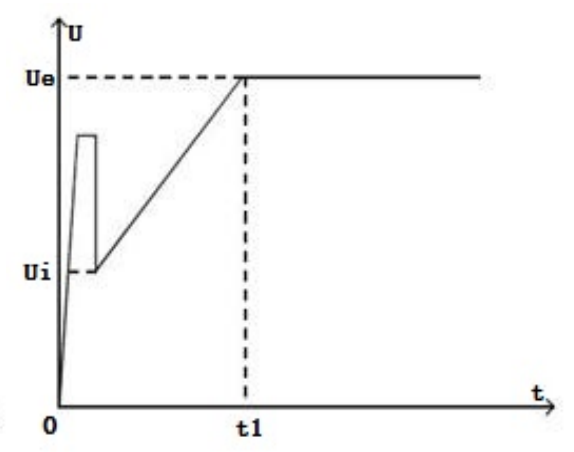

Fig.3 Jump control startup

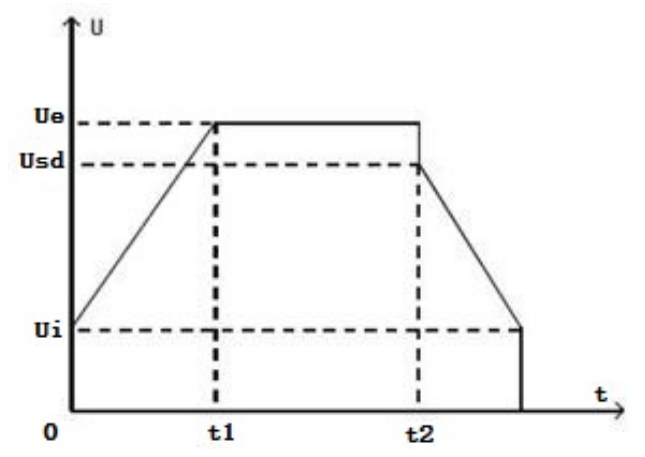

Fig.4 Soft Stop

As it suggests by Fig.2, during the operating process, the startup current is within a certain current value. It is mainly used in the voltage-reducedstartup with light load. The output voltage increases rapidly from 0 and stops until it reaches the preset current value, noted as $I q$. Then the voltage increases gradually till rated voltage under the circumstances that $I<I q$. Iq is adjustable and $I e$ is defined as rated current.

The advantage of this method is that the startup current is small, and the preset value,Iq, can be adjusted as needed (but not too small, otherwise it will lead to startup failure or burning damage of motor). The downside of this approach is the unawareness of startup voltage drop, so the D-value 
cannot be fully utilized, causing reduction of startup torque and long startup time. This approach is most practical application among the others, especially in the startup of fan-type or pump-type load.

Voltage-ramp startup transforms from step to step-less with an increasing ramp voltage. However, this method produces low starting torque and growing parabola torque characteristics which is negative to startup process. Due to the longtime of startup and destructive effects to thyristors, ramp voltage startup is seldom used in practice.

Torque control startup outputs voltages according to the linearity of the starting torque of the motor. This method has the advantages of smooth starting, good flexibility, benefitting for the dragging system. It also reduces the impact on the power grid so it's the best way in overload condition. The long starting time is the only weakness so it is popular in heavy load starting.

As shown in Fig.3, pulsive torque is used at starting instant to overcome the static torque of dragging systems to produce a smoothly growing torque to decrease the starting time of asynchronous motors. But pulsive torque will transmit sharp pulse disturbing other loads working in the systems. It is mainly used in the occasion of heavy load starting.

Voltage control startup is primarily employed in light load starting. This starting method obtains the maximum starting torque in the premise of ensuring the starting voltage drop and shortens the starting time as far as possible which is the best light load soft starting mode.

Soft stop and soft start is on the opposite condition. According to the graph shown in Fig.4, the output voltage of soft starter drops dramatically from rated voltage Ue to drop voltage Usd. With 0-12 seconds delay time preset, the output voltage of starter drops to starting voltage Ui with thyristors transferred from fully conducting state to fully closed state. And then the soft starter stops outputting to implement safety cutout of motor to avoid the torque shock caused by free cutout.

Magnetic control soft starting implements the theory of controlled magnetic limit pressure amplitude modulation. During the starting process of the asynchronous motors, the voltage drop increases smoothly from a relative lower value to full voltage increasing the motor shaft torque constantly. After that the starting characteristics become softer to realize soft stop. Nevertheless, the starting controlled voltage is fixed at $200 \mathrm{~V}$ which will produce greater current impact and the starter produced in larger volume.

High voltage soft startup mainly includeshigh-pressure liquid resistance soft starting and high pressure magnetron starting mode.Products started and protected by new type high voltage motor which is combined with advanced single chip microcomputer, semiconductor power electronics and modern control technology are adopted. This starter possesses excellent starting function which ensures the safe and reliable operations of the motors and mechanical transmission equipment.

Basic principle of the High voltage liquid resistance soft starting is making the distance of two parallel plates in liquid conductive gradually decreased to zero through a mechanical transmission device. So the resistance in series with rotor circuits smoothly decreased in order to achieve the smooth starting with heavy load and reduces the starting current impact. Practically it is normally used in the smooth starting process winding of large and medium sized electric motors. In recent year, frequency sensitive rheostat starter and metal resistance starter are gradually replaced by the water resistance.

High Voltage Magnetic Controlled Soft Starting uses the characteristics of AC effective permeability varying with the changing of DC magnetic field of ferromagnetic materials with low voltage and small power thyristor tube as the core control device in order to adjust the resistance of AC winding to realize stepless voltage regulation and smoothly control high voltage winding impedance. The startup mode needs only small power thyristor, produces tiny harmonics with stronger overload ability, at the same time, the cost of maintenance is quite considerable. 
Electromagnetic pressure soft starter is a product of new generation high voltage starter controller which overcomes the technology bottleneck of high voltage resistant of current power electronic devices. It successfully extends low voltage soft start technology to the field of soft start of high voltage. Intelligent electromagnetic soft starter which developed with the foundation of its development consists of the electromagnetic voltage regulator, power electronic power converter, intelligent control system etc. The schematic diagram of this approach is shown as Fig.5.

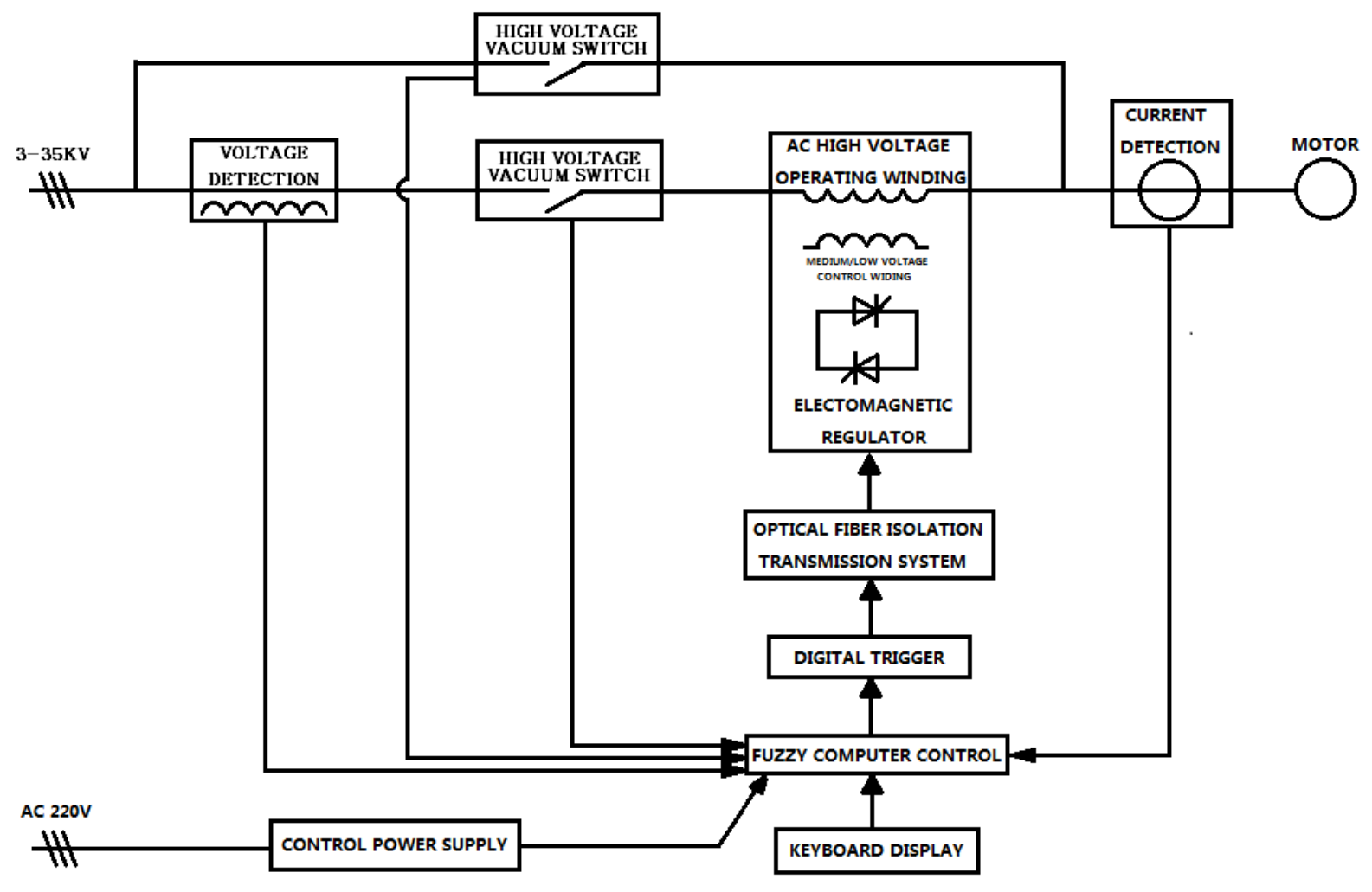

Fig.5 Intelligent Electromagnetic Voltage Regulating Startup

\section{Summary}

With the continuous emergence of new technology and new process in recent years, higher requirements of the asynchronous motor starting methods are raised. Whatever the final total is, rest assured is that the soft starters will be further applied and produce tremendous economic and social benefits with the developing of localization and the declining of raw costs.

\section{References}

[1] Wensheng Liu, OntheElectronicSoftStarterofThree-phaseAlternating CurrentAsynchronous Motor.1673-0496(2004)04-0040-03

[2] M .Popesgu,D. Micu. Analysis of a Voltage Regulator for a Two Phase Induction Motor Drive. Research Institute for Electrical Machines.

[3] R.M. Hamouda, A.I. Alolah. A Comparative Study On The Starting Methods Of Three Phase Wound Rotor Introduction Motors_PART I . IEEE TRANSACTIONS ON ENERGY CONVERSION . 1999

[4] K. Zhou. Design of Intelligent Magnetic-controlled Soft Starter for Motor. Mechanical Engineering \& Automation, 2010(05)

[5] WEI Jun-lin. Discussion on the Application of Motor Soft Starter. Shanxi 
Architecture.2013(02)

通讯信息:

联系人高长青电话 13391797087

地址: 山东省滨州市无棣小泊头镇南高村（顺丰、中通、申通）

邮编: 251900 